\title{
$\mathrm{PP}-\mathrm{g}-\mathrm{IA}$ 의 제조 및 이를 이용한 PP/EVOH 블렌드의 상용화 효과
}

\author{
김정수 · 장지훈 · 전동규 · 김동현 ${ }^{\dagger}$ \\ 한국생산기술연구원 휴먼문화융합실용화연구그룹 \\ 접수일(2014년 7월 31일), 수정일(2014년 8월 12일), 게재확정일(2014년 8월 25일)
}

\section{Preparation of PP-g-IA and its Compatibilizing Effects in PP/EVOH Blends}

\author{
Jung Soo Kim, Ji-hoon Jang, Dong-gyu Jeon, and Dong Hyun Kim ${ }^{\dagger}$ \\ Human and Culture Convergence Technology R\&BD Group, Korea Institute of Industrial Technology, Ansan-si, \\ Gyeonggi-do, 426-910, Republic of Korea
}

(Received July 31 , 2014, Revised August 12, 2014, Accepted August 25, 2014)

\begin{abstract}
요 약 : 본 연구에서는 폴리프로필렌 $(\mathrm{PP})$ 과 에틸렌 비닐알코올 공중합체 (EVOH) 의 블렌드에 있어 발생하는 상분리 현상을 방지하고자 PP에 itaconic acid (IA)가 그라프트 된 PP-g-IA 를 상용화제로 이용하였다. PP-g-IA 상용화 제는 PP base에 IA의 투입량을 1, 2, 5, 10 wt.\% 로 달리하면서 투입하여 제조하였으며, FT-IR과 ${ }^{1} \mathrm{H} \mathrm{NMR}$ 분석을 통하여 성공적으로 PP에 IA가 그래프트 되었음을 확인하였다. 이 중 그래프트율이 $1 \%$ 로 가장 높게 나타난 PP-g-IA 상용화제를 $\mathrm{PP} / \mathrm{EVOH}$ 블렌드 연구에 적용하였다. 신규 상용화제가 적용된 $\mathrm{PP} / \mathrm{EVOH}$ 블렌드는 $\mathrm{SEM}$ 을 이용하여 모폴로지를 관찰하였고, DSC 와 UTM를 이용하여 열적·기계적 특성을 분석하였다. 분석 결과, PP-g-IA 상용화제 는 $\mathrm{PP} / \mathrm{EVOH}$ 블렌드의 계면접착력을 향상시키는 것으로 나타나 상용화제로써의 유효성이 확인되었다.
\end{abstract}

\begin{abstract}
In this study, we used polypropylene grafted with itaconic acid (PP-g-IA) as a compatibilizer to prevent phase separation phenomenon which occurs upon blending polypropylene (PP) and ethylene-vinyl alcohol copolymer (EVOH). A compatibilizer was prepared using graft copolymerization of itaconic acid (IA) onto PP where input ratio of IA was 1,2 , 5, and 10 wt.\%. To confirm the structure of PP-g-IA and the graft ratio of IA onto PP, we used ${ }^{1} \mathrm{H}$ NMR and FT-IR. We tested the compatibilizer which has highest graft ratio of $1 \%$ in immiscible PP/EVOH blends. The morphologies of PP/PP-g-IA/EVOH blends were analyzed by SEM. Thermal and mechanical properties of the blends were analyzed by DSC and UTM. PP-g-IA enhanced the interfacial adhesion of PP and EVOH copolymer.
\end{abstract}

Keywords : PP/EVOH, blend, compatibilizer, itaconic acid, graft copolymerization

\section{I . 서 론}

식품 포장분야에서는 식품의 안정성, 보호성, 장기 보존성 등의 연구가 활발히 이뤄짐에 따라 식품 산업의 발전을 가능 하게 하고 있다. 식품포장용 소재는 제품의 안정된 유통기한 을 확보하기 위하여 기체와 수분에 대한 차단성, 가격경쟁력 과 기계적 강도를 동시에 충족할 수 있어야 한다. ${ }^{1-2}$

현재 식품 포장에서 널리 사용되고 있는 대표적인 포장 소 재로는 polypropylene (PP) 과 ethylene-vinyl alcohol 공중합체 $(\mathrm{EVOH})$ 가 있으며, $\mathrm{PP}$ 는 저가이면서 수분에 대한 차단성이 우수하고, $\mathrm{EVOH}$ 는 내화학성과 기체 차단성이 우수한 것으로 알려져 있다. ${ }^{3} \mathrm{EVOH}$ 는 $\mathrm{OH}$ 기에 의한 수분 취약성이 단점이 기 때문에 $\mathrm{PP}$ 를 배리어 층으로 사용하여 $\mathrm{PP} / \mathrm{EVOH} / \mathrm{PP}$ 의 다 층구조 형태로 제조되기도 한다. 이 경우, 기체와 수분에 대한

\footnotetext{
${ }^{\dagger}$ Corresponding Author. E-mail: dhkim@kitech.re.kr
}

차단성이 동시에 높아져 식품의 보존성을 증가시키는 장점이 있으나, 별도의 장비나 공정이 필요하기 때문에 비용이 상승 하게 되고 최종 제품은 재활용이 불가하다는 단점이 있다.4-6 $\mathrm{Yeo}$ 등은 $\mathrm{PP}$ 와 $\mathrm{EVOH}$ 를 블렌딩한 후 이축 연신 공정을 도입 하여 저가이면서 PP 보다 향상된 차단성을 나타내는 필름을 제조하였으며, PP 에 maleic anhydride 가 그래프트된 상용화제 인 PP-g-MAH 를 적정량 적용하여 양호한 분산상태 및 산소 차단성이 증가하는 효과를 확인 하였다. ${ }^{7}$

상용화제는 $\mathrm{PP}$ 와 $\mathrm{EVOH}$ 블렌드와 같이 분자구조의 차이에 따라 상분리가 나타날 수 있는 소재 간의 결합력을 향상시키기 위하여 필수적으로 첨가해야 하며 이와 관련한 연구는 다수 보고된 바 있다. ${ }^{8-9}$ Ares 등은 $\mathrm{PP} / \mathrm{EVOH}$ 블렌딩에 ionomer 를 상 용화제로 적용하여 유변학적 특성변화와 모폴로지를 관찰하였 으며, ${ }^{10}$ Fisher 등은 mica, glass beads, PP-g-MAH 를 상용화제로 첨가하여 $\mathrm{PP} / \mathrm{EVOH}$ 블렌드의 물성을 비교하였다. ${ }^{11}$ Yousefi 등 은 $\mathrm{PP} / \mathrm{EVOH}$ 블렌딩 필름을 제조하기 위하여 PP-g-MAH 와 di- 
ethyl maleate 가 그래프트된 PP-g-DEM를 상용화제로 첨가하였 으며, 연신공정을 거쳐 기계적 물성과 모폴로지, 기체 차단성 등을 비교하였다. ${ }^{12}$ 뿐만 아니라, Chun 과 $\mathrm{Ahn}$ 은 $\mathrm{PP} / \mathrm{EVOH} / \mathrm{PP}$ 다층구조의 필름 제조시 발생하는 스크랩과 $\mathrm{PP}$ 를 블렌딩하기 위하여 다양한 상용화제를 비교 적용하였는데, ${ }^{4}$ 이와 같이 상용 화제는 $\mathrm{PP} / \mathrm{EVOH}$ 블렌드의 물성을 결정짓는 매우 중요한 요소 중의 하나라 할 수 있다.

따라서 본 연구에서는 PP matrix 에 itaconic acid 가 그래프 트된 PP-g-IA 상용화제를 제조하여 상용성이 낮은 $\mathrm{PP} / \mathrm{EVOH}$ 블렌드에 적용하고, 상용화제 첨가량에 따른 블렌드 모폴로지 와 열적·기계적 특성 변화를 관찰하였다.

\section{II. 실 험}

\section{1. 재료 및 방법}

$\mathrm{PP}$ 는 폴리미래(주)의 HP 552N (MFI: $14 \mathrm{~g} / 10 \mathrm{~min}$ )을 사용하 였고, 개시제로는 2,5-bis(tert-butylperoxy)-2,5-dimethylhexane (Aldrich 90\%)을 사용하였다. 블렌드에 사용한 $\mathrm{EVOH}$ 는 EVAL Europe 의 F101B (EVOH content: 32.9\%, MI: $1.51 \mathrm{~g} / 10$ $\mathrm{min}$ ) 을 사용하였다. Itaconic acid (Aldrich $99 \%$, 이하 IA)는 사용 전 수분제거를 위해 8 시간 이상 진공건조 하였고, 정제 를 위해 xylene (Samchun 99\%), acetone (Samchun 98\%) 및 methanol (Samchun 98\%)을 사용하였다.
상용화제 제조 과정으로는 브라벤더 믹서 (Brabender $\mathrm{GmbH}$, Plasti-Corder 680135 type)를 이용하여 $190{ }^{\circ} \mathrm{C}, 70 \mathrm{rpm}$ 조건에서 $\mathrm{PP}$ 를 투입하여 melt 상태로 만든 후, 개시제와 IA 를 차례대로 투입한 뒤 $6 \mathrm{~min}$ 동안 반응을 진행하였다. 제조과정에서 투입 된 PP, IA 및 개시제의 양은 Table 1에 정리되어 있다. 이후 정제과정으로 생성된 물질을 hot xylene 에 용해시킨 뒤 acetone 에 의해 재결정시켜 미반응 단량체를 제거시켰다. 이후 24 시간 동안 methanol 을 용매로 한 soxhlet 장치를 이용하여 불순물인 개시제, 미반응 단량체 및 homopolymer 등을 제거하 였다.

제조된 상용화제의 그래프트율은 FT-IR 을 이용하여 M. Yazdani-Pedram 등이 제시한 방법에 따라 IA 투입량에 따라 $\mathrm{PP}$ 에 해당하는 $1167 \mathrm{~cm}^{-1}$ 와 IA 의 해당하는 $1710 \mathrm{~cm}^{-1}$ 의 transmittance 비를 측정하여 calibration curve 를 유도한 뒤 제 조된 상용화제의 FT-IR spectrum 에서 측정된 transmittance 값 을 이용해 역추산 하는 방법으로 계산하였으며, ${ }^{13}$ 제조된 상용 화제는 PP-g-IA (graft ratio) 형태로 표기하였다.

상용화제 PP-g-IA 를 투입한 PP 와 EVOH 의 블렌드의 제조 는 브라벤더 믹서 (Brabender $\mathrm{GmbH}$, Plasti-Corder 680135 type) 를 이용하였다. 제조 조건으로는 $190{ }^{\circ} \mathrm{C}, 50 \mathrm{rpm}, 10 \mathrm{~min}$ 으로 설정하였고, $\mathrm{PP}$ 와 $\mathrm{EVOH}$ 의 투입량은 $90 / 10$ 으로 고정시킨 채, 상용화제의 투입량을 변화시켜 실험을 진행하였다. 제조 한 블렌드 물질 명은 Table 2 와 같이 표기하였고 이 때 괄호 안에 표기한 상용화제의 투입함량의 단위는 phr (parts per hundred)로 나타내었다.

Table 1. Summarization of Graft Copolymerization of IA onto PP

\begin{tabular}{|c|c|c|c|c|c|}
\hline Name & PP (g) & Initiator $^{\mathrm{a}}(\mathrm{g})$ & IA (g) & IA (wt. \%) & Graft ratio $^{\mathrm{b}}(\%)$ \\
\hline PP-g-IA 0.75 & 24.75 & 0.247 & 0.25 & 1 & 0.75 \\
\hline PP-g-IA ${ }_{0.90}$ & 24.50 & 0.245 & 0.50 & 2 & 0.90 \\
\hline PP-g-IA 1.00 & 23.75 & 0.237 & 1.25 & 5 & 1.00 \\
\hline PP-g-IA 0.89 & 22.50 & 0.225 & 2.50 & 10 & 0.89 \\
\hline
\end{tabular}

a. Initiator content: 1 wt. \% of PP

b. Determined by FT-IR

Table 2. Summarization of PP/EVOH Blend and PP/PP-g-IA/EVOH Blends

\begin{tabular}{|c|c|c|c|}
\hline Name & $\mathrm{PP}(\mathrm{g})$ & EVOH (g) & PP-g-IA ${ }_{1.00}(\mathrm{~g})$ \\
\hline $\mathrm{PP} / \mathrm{EVOH}$ & 31.5 & 3.5 & 0 \\
\hline PP/PP-g-IA $1.00(2.5) / E V O H$ & 31.5 & 3.5 & 0.875 \\
\hline PP/PP-g-IA ${ }_{1.00}(5) / E V O H$ & 31.5 & 3.5 & 1.75 \\
\hline PP/PP-g-IA $1.00(10) / E V O H$ & 31.5 & 3.5 & 3.5 \\
\hline PP/PP-g-IA $1.00(20) / E V O H$ & 31.5 & 3.5 & 7 \\
\hline
\end{tabular}




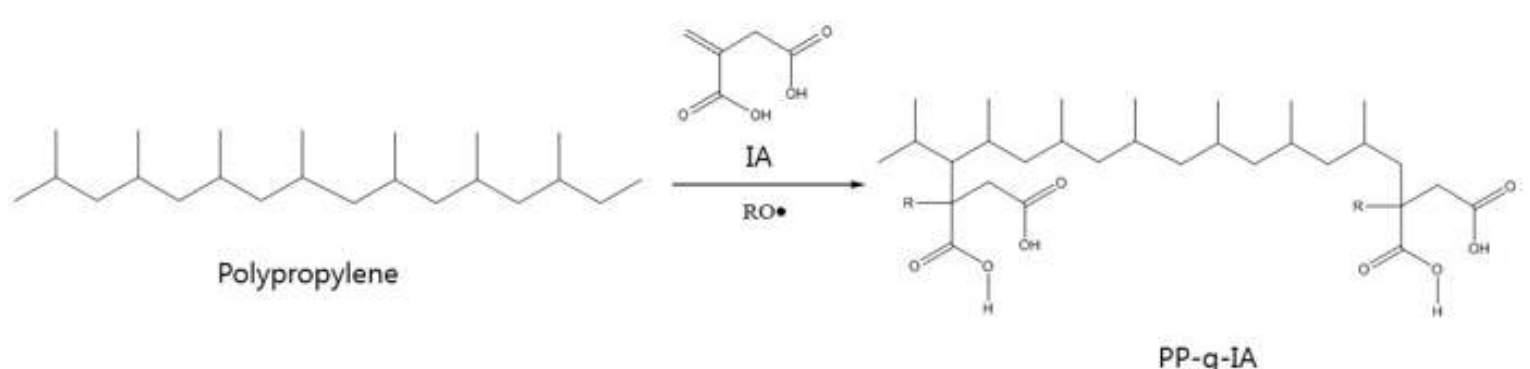

$R=H, I A, P P$

Scheme 1. Synthetic procedures of PP-g-IA

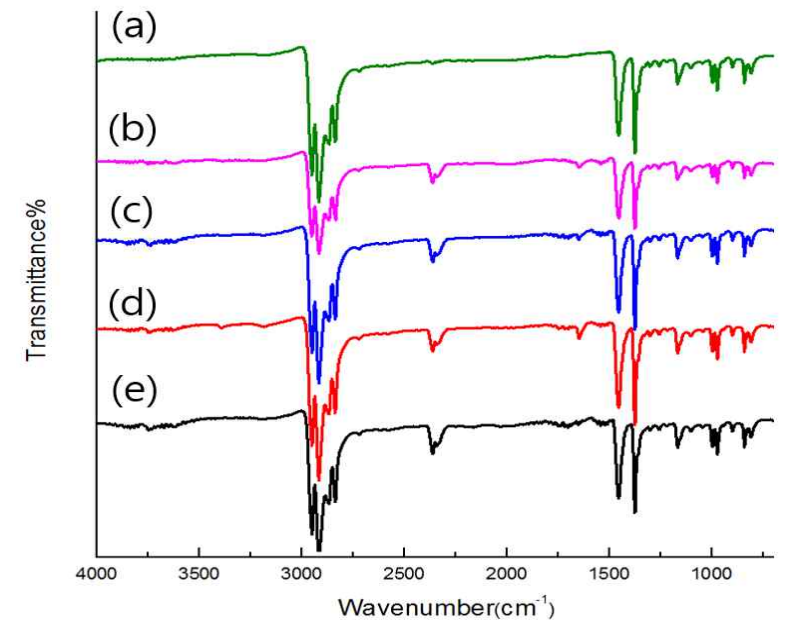

Figure 1. IR spectra of (a) PP, (b) PP-g-IA ${ }_{0.79}$, (c) PP-g-IA $\mathrm{I}_{0.90}$, (d) PP-g-IA 1.00 , and (e) PP-g-IA 0.89 .

\section{2. 분석 기기 및 조건}

상용화제의 구조 분석을 위해 Bruker 사의 AVANCE 400, $500 \mathrm{MHz}$ 모델인 ${ }^{1} \mathrm{H} \mathrm{NMR}$ 를 사용하여 $50{ }^{\circ} \mathrm{C}$ 에서 $\mathrm{CDCl}_{3}$ 용매 에 용해시켜 분석하였다.

직접 제조한 상용화제의 구조는 Nexus (Thermo Nicolet)에 서 제작한 Fourier transform infrared spectroscopy (FT-IR)을 이 용하여 분석하였다.

Perkin Elmer 사의 DSC (TAC7)를 이용하여 $\mathrm{T}_{\mathrm{m}}$ 을 측정하였 으며, $-50-200{ }^{\circ} \mathrm{C}$ 의 온도 범위에서 온도를 $10{ }^{\circ} \mathrm{C} / \mathrm{min}$ 간격으로 1 차 승온 시킨 후, 곧바로 2 차 냉각을 하고, 다시 3 차 승온을 시키며 측정하였으며, 시료의 양은 $10 \mathrm{mg}$ 으로 한 시편당 두 번씩 정밀하게 분석하여 제조된 블렌드 및 상용화제의 열적거 동 특성을 확인하였다.

Tinius Olsen 사의 H5K-T 모델인 Universal Testing Machine (UTM) 인장 시험기를 사용하여 신율 $(\%)$, 파단강도 (MPa) 및 모듈러스 $(\mathrm{GPa})$ 를 구하였으며, 이 때 crosshead speed 는 50 $\mathrm{mm} / \mathrm{min}$ 으로 설정하였다. 신율은 재료 인장시험 시 재료가

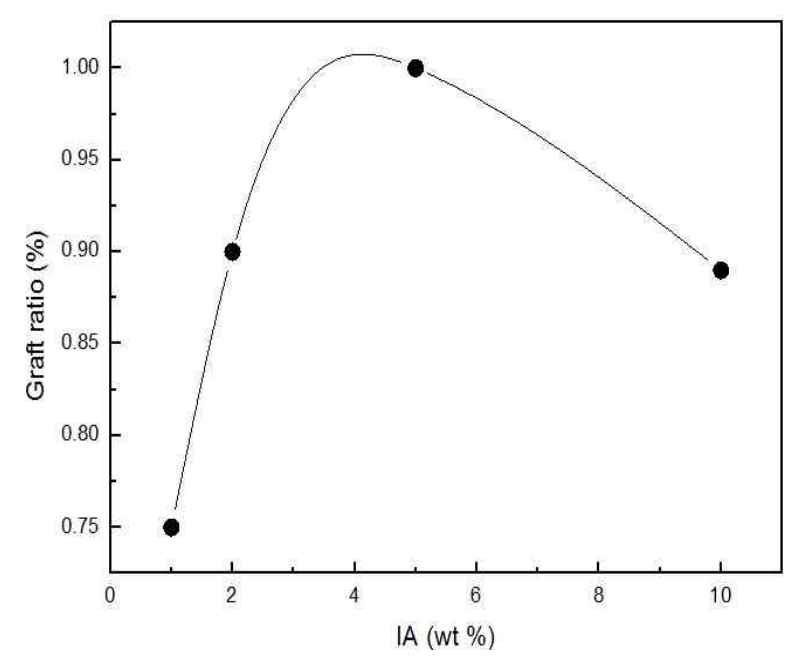

Figure 2. Changes of graft ratio of IA onto PP according to IA input content.

늘어나는 비율을 말하며, 파단강도는 시험재료가 외력에 의해 파단 될 때 생긴 응력을 $\mathrm{MPa}$ 단위로 나타낸 것을 의미한다.

\section{III. 결과 및 고찰}

\section{1. $\mathrm{PP}-\mathrm{g}-\mathrm{IA}$ 구조 분석}

\section{1-1. FT-IR 의한 PP-g-IA 구조 분석}

PP-g-IA 의 구조를 FT-IR 과 ${ }^{1} \mathrm{H}-\mathrm{NMR}$ 을 통하여 확인하였다. Figure 1 과 같이 PP 단독수지와 PP-g-IA 상용화제의 FT-IR 측 정 결과, 모든 물질에서 공통적으로 $\mathrm{PP}$ 의 $\mathrm{C}-\mathrm{H}$ stretch 해당하 는 피크가 $2900 \mathrm{~cm}^{-1}$ 부근에서 관찰된 반면, PP-g-IA 에서는 $\mathrm{PP}$ 에서 나타나지 않은 IA 의 carbonyl group 피크가 $1710 \mathrm{~cm}^{-1}$ 부근에서 나타나는 것을 확인할 수 있었다.

Figure 2 는 개시제 함량이 일정할 때, IA 의 투입량에 따른 그래프트율의 변화를 나타낸 그래프이다. IA 투입 함량이 1 wt. \% 에서 5 wt. \%까지 증가함에 따라 그래프트율이 증가하 는 것을 확인하였으나, $10 \mathrm{wt} \%$ 에서는 오히려 감소되는 것이 
확인되었다. 이는 개시제 대비 IA 투입량이 높아져 IA 의 homopolymerization 이 발생하였기 때문으로 판단된다.

\section{1-2. ${ }^{1} \mathrm{H}-\mathrm{NMR}$ 에 의한 PP-g-IA 구조 분석}

Figure 3은 합성된 PP-g-IA 의 ${ }^{1} \mathrm{H}-\mathrm{NMR}$ spectrum 이다. 분석 결과, $\mathrm{PP}$ 에 존재하는 methyl proton, methylene proton, methane proton 이 0.9 1.6 ppm 에서 나타나는 것을 확인할 수 있었다. $2.1 \mathrm{ppm}$ 부근에서는 singlet 형태의 피크가 약하게 나타나는 것을 확인하였는데, 이는 graft 중합된 IA 의 methylene 그룹의 proton 에 의한 피크인 것을 확인할 수 있다. 이를 토대로 PP 에 $\mathrm{IA}$ 가 성공적으로 그래프트 되었음을 확인할 수 있었다.

\section{PP/PP-g-IA/EVOH 블렌드의 특성 분석}

\section{2-1. 모폴로지 특성 분석}

Figure 4 는 PP 단독수지, $\mathrm{PP} / \mathrm{EVOH}$ 블렌드 및 $\mathrm{PP} / \mathrm{EVOH}$ 에 PP-g-IA 를 투입 함량을 변화시켜가면서 제조한 블렌드를 $\mathrm{SEM}$ 을 이용하여 측정한 결과이다. PP-g-IA 를 첨가하지 않았
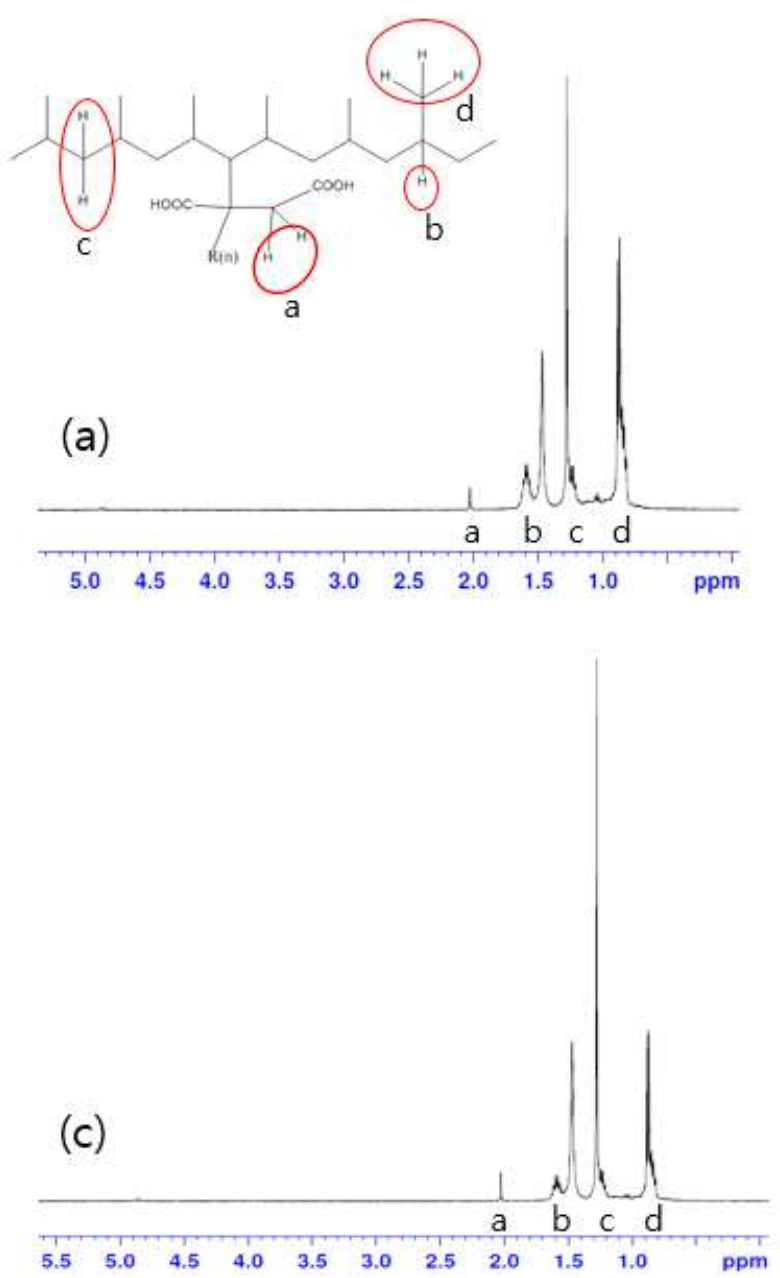

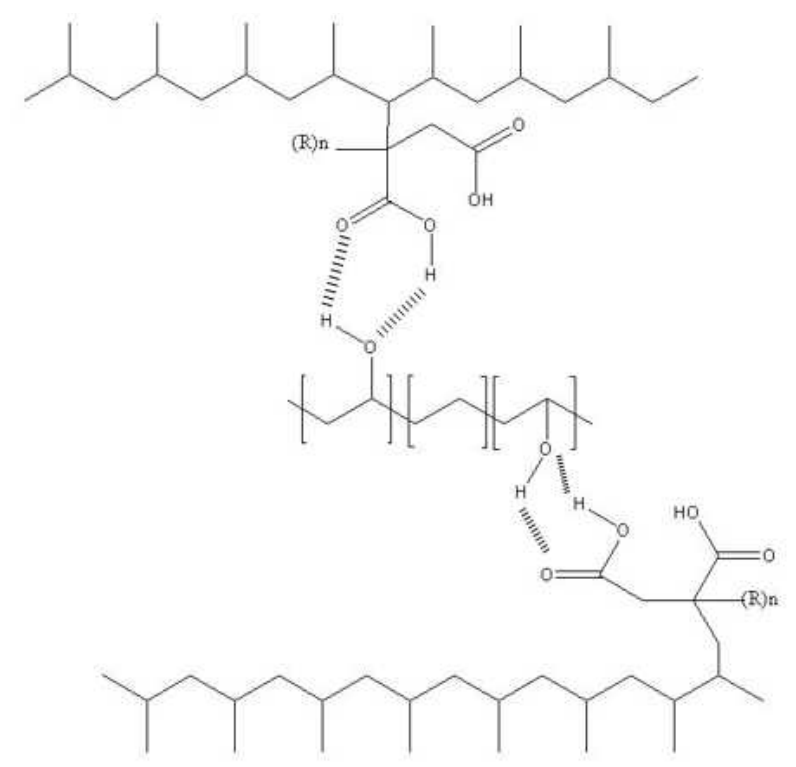

Scheme 2. Supermolecular hydrogen bonding in PP/PP-g-IA/EVOH blends.
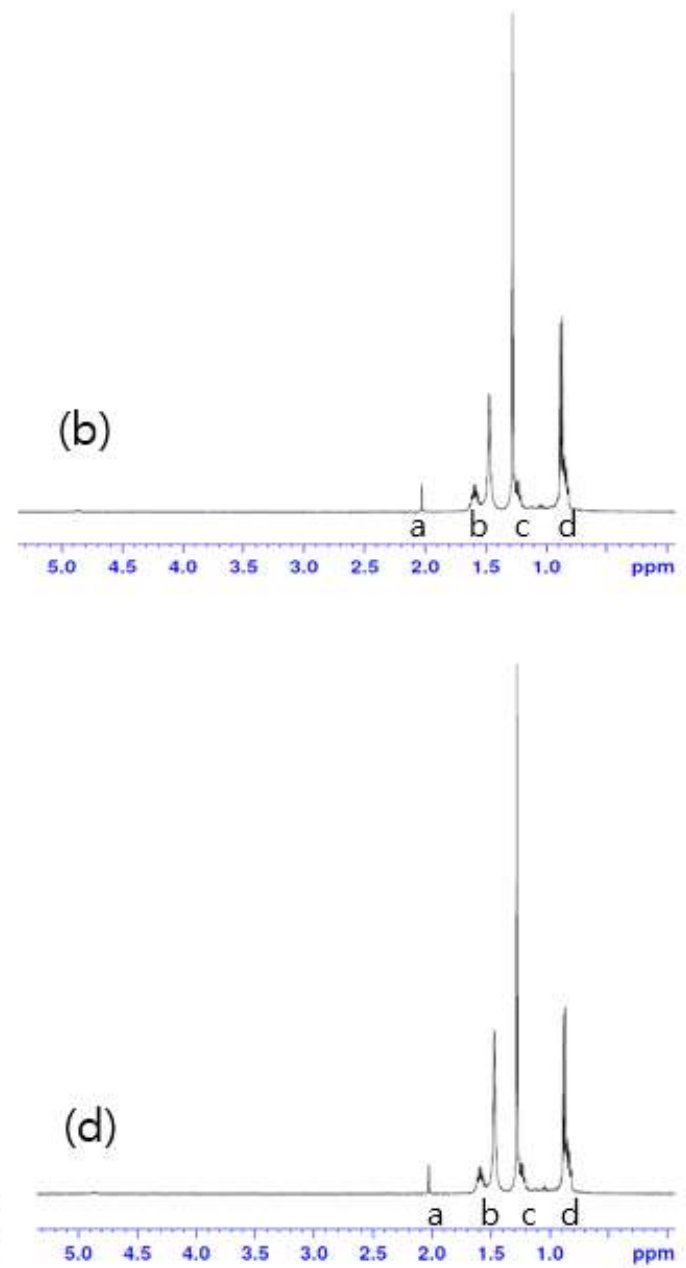

Figure 3. ${ }^{1} \mathrm{H}-\mathrm{NMR}$ spectra of (a) PP-g-IA $\mathrm{IA}_{0.79}$, (b) PP-g-IA $\mathrm{I}_{0.90}$, (c) PP-g-IA $\mathrm{I}_{1.00}$, and (d) PP-g-IA $\mathrm{A}_{0.89}$. 


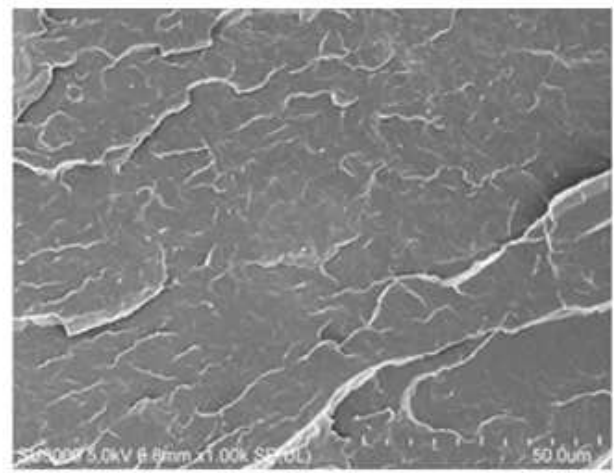

(a) PP

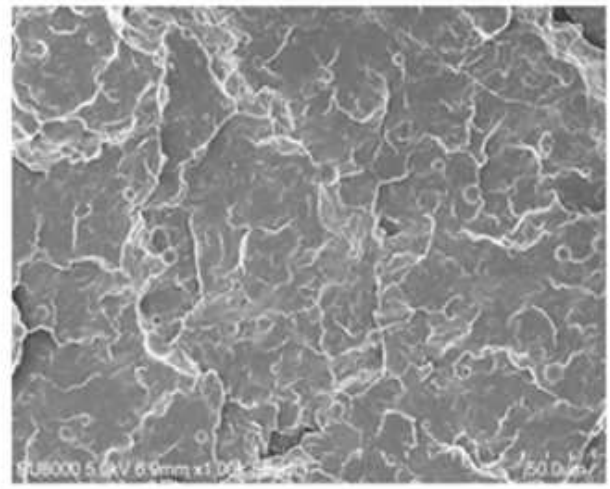

(c) PP/PP-g-IA $1.00(2.5) / E V O H$

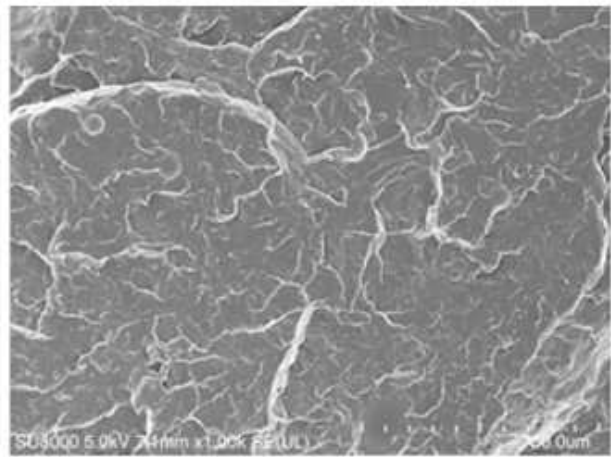

(e) PP/PP-g-IA $1.00(10) / E V O H$

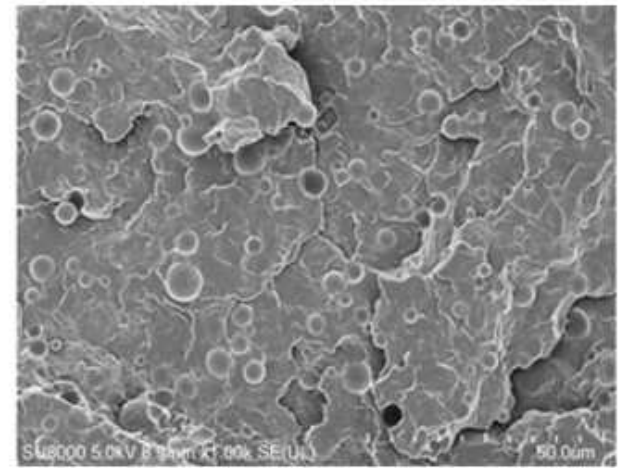

(b) PP/EVOH

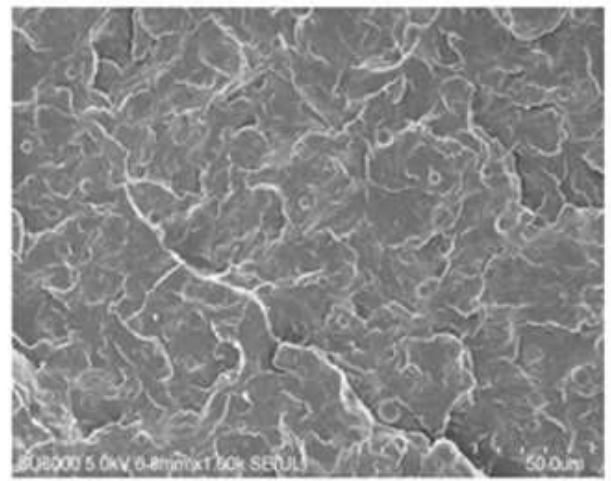

(d) PP/PP-g-IA $1.00(5) / E V O H$

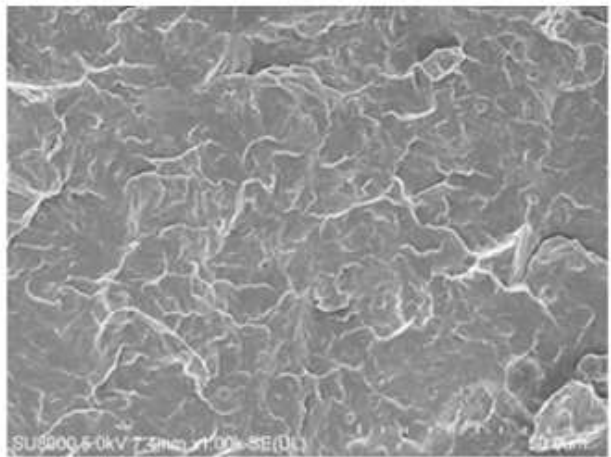

(f) PP/PP-g-IA 1.00 (20)/EVOH

Figure 4. SEM images of PP homopolymer, PP/EVOH blend, and PP/PP-g-IA/EVOH blends with various compatibilizer content.

을 경우, Figure 4-b 와 같이, $\mathrm{PP}$ 와 $\mathrm{EVOH}$ 의 상이 뚜렷하게 구분되는 것을 확인할 수 있다. 반면 PP-g-IA 의 투입량이 2.5 $\mathrm{Phr}$ 에서 $20 \mathrm{Phr}$ 까지 증가할수록 두 상의 계면 접착력이 증가 하는 것을 확인할 수 있었다. 또한 PP-g-IA 의 투입량이 증가 할수록 PP 매트릭스 내에서 $\mathrm{EVOH}$ 의 입자크기가 뚜렷하게 감소하는 것을 확인할 수 있었다.

이는 Scheme 2에 나타낸 바와 같이 상용화제인 PP-g-IA 가 투입됨에 따라 IA 에 존재하는 carbonyl 기와 $\mathrm{EVOH}$ 에 존재하 는 hydroxyl 기 사이에 수소결합이 발생하여, $\mathrm{PP}$ 와 $\mathrm{EVOH}$ 와 의 상분리 현상을 억제하였고, 이에 따라 계면 접착력이 증가
된 것으로 판단되었다. 결과적으로 원래 섞이지 않는 $\mathrm{PP} / \mathrm{EVOH}$ 블렌드에 있어서 PP-g-IA 가 유효한 상용화제로의 역할을 하는 것을 확인할 수 있었다.

\section{2-2. 열적특성 분석}

Figure 5 는 PP, EVOH, PP/EVOH 블렌드 및 PP/PP-g-IA/EVOH 블렌드의 DSC 그래프이다. 블렌드에 있어서 $\mathrm{EVOH}$ 의 녹는점 $\left(\mathrm{T}_{\mathrm{m}}\right)$ 은 투입한 상용화제의 함량이 증가할수록 감소하는 특성 을 나타내었는데, 이는 상용화제의 함량이 증가함에 따라 PP 와 $\mathrm{EVOH}$ 두 상의 계면 접착력이 증가하기 때문에 $\mathrm{EVOH}$ 상의 


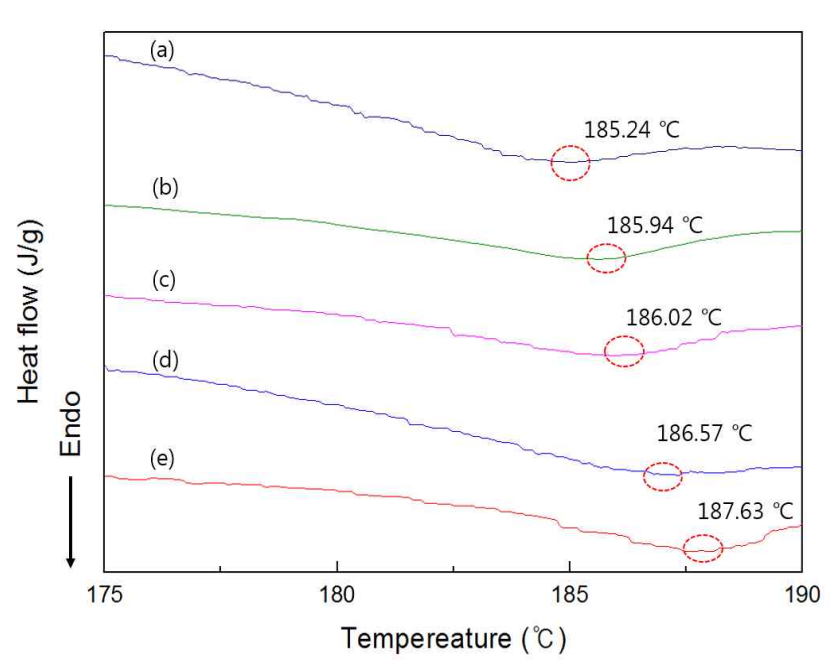

Figure 5. DSC data of (a) PP/PP-g-IA $\mathrm{I}_{1.00}(20) / \mathrm{EVOH}$, (b) PP/PP-g-IA $\mathrm{IA}_{1.00}$ (10)/EVOH, (c)PP/PP-g-IA 1.00 (5)/EVOH, (d) PP/PP-g-IA 1.00 (2.5)/EVOH, (e) $\mathrm{PP} / \mathrm{EVOH}$.

Table 3. Tensile Properties of PP/EVOH blend and PP/PP-g-IA/EVOH blends

\begin{tabular}{c|c|c|c}
\hline Name & $\begin{array}{r}\text { Ultimate Tensile } \\
\text { Strength (MP) }\end{array}$ & $\begin{array}{c}\text { Tensile Modulus } \\
(\mathrm{MPa})\end{array}$ & $\begin{array}{c}\text { Elongation at } \\
\text { break (\%) }\end{array}$ \\
\hline PP/EVOH & 25.5 & 243.5 & 10.1 \\
\hline PP/PP-g-IA1.00 (2.5)/EVOH & 26.3 & 244.0 & 11.3 \\
\hline PP/PP-g-IA1.00 (5)/EVOH & 23.4 & 259.0 & 11.6 \\
\hline PP/PP-g-IA1.00 (10)/EVOH & 25.1 & 178.0 & 12.4 \\
\hline PP/PP-g-IA1.00 (20)/EVOH & 27.2 & 173.0 & 15.5 \\
\hline
\end{tabular}

$\mathrm{T}_{\mathrm{m}}$ 이 Matrix 인 PP 쪽으로 이동하는 것으로 판단된다. 반면 $\mathrm{PP}$ 의 $\mathrm{T}_{\mathrm{m}}$ 은 상용화제의 투입으로 인해 감소하는 것으로 나타 났는데, 이는 상용화제 투입 및 $\mathrm{EVOH}$ 와의 블렌드에 따른 $\mathrm{PP}$ 의 결정화도 감소가 주요한 원인으로 판단된다.

\section{2-3. 기계적 물성 분석}

Table 3 은 PP/EVOH 및 PP/PP-g-IA/EVOH 블렌드의 기계적 물성을 정리한 표이다. 파단 강도의 경우 $23 \sim 28 \mathrm{MPa}$ 의 범위 에서 나타났다. 상용화제의 함량에 따른 파단 강도의 경향성 은 나타나지 않았으나, 신율의 경우 상용화제의 함량이 증가 할수록 값이 증가하는 것을 확인할 수 있다. $10 \mathrm{phr}$ 이상의 상용화제 투입 시 블랜드의 Modulus 가 감소되는 것이 확인되 었다. 이는 상용화제 제조시 개시제에 의해 PP 가 분해되어 상용화제에는 낮은 분자량의 PP 가 많이 존재하게 되고, 이로 인해 일정량 이상의 상용화제를 투입하면 블랜드의 modulus 가 감소하는 것으로 판단된다.

\section{$\mathrm{IV}$. 결 론}

본 실험에서는 $\mathrm{PP} / \mathrm{EVOH}$ 블렌드의 비상용성을 극복하기 위 하여 PP matrix 에 IA 가 그래프트된 PP-g-IA 상용화제를 직접 제조하고, $\mathrm{PP} / \mathrm{EVOH}$ 블렌드에 적용하였으며 상용화제 투입량 에 따른 모폴로지와 열적·기계적 특성 변화를 관찰하였다. 제조한 PP-g-IA 상용화제는 FT-IR 및 ${ }^{1} \mathrm{H}-\mathrm{NMR}$ 를 통해 구조를 확인하였는데, FT-IR 측정 결과, PP-g-IA 에서는 PP 에서 나타 나지 않는 $1710 \mathrm{~cm}^{-1}$ 부근의 IA 의 carbonyl group 의 피크가 관찰되었다. ${ }^{1} \mathrm{H}-\mathrm{NMR}$ 분석결과에서는 $2.1 \mathrm{ppm}$ 에서 $\mathrm{IA}$ 의 methylene 그룹 proton 에 의한 피크가 singlet 형태로 나타나 $\mathrm{PP}$ 에 IA 가 성공적으로 그래프트 되었음을 확인할 수 있었다. 또한, 투입한 IA 의 양이 증가할수록 그래프트 되는 IA 의 비 율이 높아지는 것을 확인하였으나, 일정량 이상의 IA 가 투입 되면 오히려 그래프트율이 감소하는 것이 확인되었다.

제조된 PP-g-IA 가 적용된 PP/EVOH 블렌드의 SEM 분석결 과, PP-g-IA 투입량이 증가할수록 $\mathrm{PP}$ 와 $\mathrm{EVOH}$ 의 계면 접착력 이 향상되는 것을 확인할 수 있었다. 이는 상용화제에 존재하 는 IA 의 carbonyl 기와 EVOH 에 존재하는 hydroxyl 기 사이에 수소결합이 발생하여, $\mathrm{PP}$ 와 $\mathrm{EVOH}$ 와의 계면 접착력이 향상 된 것으로 사료된다.

DSC 측정 결과에서는 PP-g-IA 의 함량이 높아질수록 $\mathrm{EVOH}$ 의 $\mathrm{T}_{\mathrm{m}}$ 이 낮아졌으며, 파단 강도의 경우 $23-28 \mathrm{MPa}$ 의 범위에서 나타났고, 상용화제의 투입 함량이 증가함에 따라 신율 값이 소폭 증가하는 것을 확인할 수 있었다.

본 연구에서는 비 상용계로 알려진 $\mathrm{PP} / \mathrm{EVOH}$ 블렌드에 이 용할 수 있는 상용화제를 직접 합성하였으며, 제조된 상용화 제를 블렌드에 적용하여 적정 투입량을 선정하는 일련의 과정 을 수행하였다. 결과적으로 제조된 PP-g-IA 는 PP/EVOH 블렌 드의 물성을 향상시켰고, 이에 따라 상용화제로써의 활용이 가능함을 확인하였다.

\section{References}

1. A. Lopez-Rubio, P. Hernandez-Munoz, E. Gimenez, T. Yamamoto, R. Gavara, and J. M. Lagaron, Gas Barrier Changes and Morphological Alterations Induced by Retorting in Ethylene Vinyl Alcohol-Based Food Packaging Structures, J. Appl. Polym. Sci., 96, 2192 (2005).

2. P. H. P. Macaubas, N. R. Demarquette, and J. M. Dealy, Nonlinear viscoelasticity of PP/PS/SEBS blends, Rheol. Acta., 44, 295 (2005).

3. J. T. Yeh, W. H. Yao, Q. Du, and C. C. Chen, Blending and Barrier Properties of Blends of Modified Polyamide and Ethylene Vinyl Alcohol Copolymer, J. Polym. Sci. Part B Polym. Phys., 43, 511 (2005). 
4. Y. J. Chun, and T. K. Ahn, The Thermal and Mechanical Properties of Recycled PP/EVOH/PP Scrap with Compatibilizers, Kor. Acad-Ind. Coop. Soc., 9, 176 (2008).

5. M. J. Abad, A. Ares, L. Barral, and J. I. Eguizabal, Influence of the ethylene-(methacrylic acid) $\mathrm{Zn}^{2+}$ ionomer on the thermal and mechanical properties of blends of poly(propylene) (PP)/ethylene-(vinyl alcohol) copolymer (EVOH), Polym. Int., 54, 673 (2005).

6. A. Ares, J. Silva, J. M. Mania, L. Barralm, and M. J. Abad, Rheomechanical and morphological study of compatibilized PP/EVOH blends, Rheol. Acta., 48, 993 (2009).

7. J. H. Yeo, C. H. Lee, C. S. Park, and K. J. Lee, Rheological, Morphological, Mechanical, and Barrier Properties of PP/EVOH Blends, Adv. Polym. Tech., 20, 191 (2001).

8. J. Silva, A. V. Machado, J. M. Maia, Rheological behavior of compatibilized and non-compatibilized PA6/EPM blends, Rheol. Acta., 46, 1091 (2007).
9. J. S. Hong, J. L. Kim, K. H. Ahn, and S. J. Lee, Interface Modification and Characterization in Three-Component Polymer Blends, J. Appl. Polym. Sci., 97, 1702 (2005).

10. M. Montoya, M. J. Abad, L. Barral, and C. Bernal, Mechanical and fracture behavior of polypropylene/poly(ethylene-co-vinyl alcohol) blends compatibilized with ionomer $\mathrm{Na}^{+}$, Eur. Polym. J., 42, 265 (2006).

11. I. Fishier, J. Zoldan, and A. Siegmann, Barrier and physical properties of polypropylene/highbarrier ethylene vinyl alcohol copolymer blends compatibilized with a sodium ionomer, Polym. Comp., 21, 476 (2000).

12. A. A. Yousefi and A. K. Abdellatif, Effects of Compatibilizer and Post-extrusion Stretching on Properties of Plastic Barrier Films, Iran. Polym. J., 14, 411 (2005).

13. M. Yazdani-Pedram, H. Vega, and R. Quijada, Melt grafting of itaconic acid and its derivatives onto an ethylene-propylene copolymer, Macromol. Chem. Phys., 199, 2495 (1998). 